\title{
IMPLICACIÓN DE LA CONFIANZA EN LA SOSTENIBILIDAD EMPRESARIAL ${ }^{1}$
}

\author{
Nelson Díaz Cáceres ${ }^{2}$ \\ Luz Janeth Lozano Correa ${ }^{3}$ \\ Carlos Andrés Castaño Quintero ${ }^{4}$
}

Para citar este artículo: Díaz, N., Lozano, L., y Castaño, C. (2016). Implicación de la confianza en la sostenibilidad empresarial. Inquietud Empresarial. Vol. XVI (1), 83-114

Fecha de recepción: 17 de septiembre de 2015

Fecha de aceptación: 29 de abril de 2016

\footnotetext{
${ }^{1}$ Artículo de reflexión. El presente trabajo forma parte del proyecto de investigación "Incidencia de la confianza en las empresas sostenibles" durante los años 2014 y 2015 de la Universidad EAN. El estudiante Edgar Leandro Acevedo apoyó en los procesos de investigación como monitor.

${ }^{2}$ Doctor en administración por valores. Magíster gestión organizaciones. Director Departamento Gestión Cultural y Socio humanística. Docente titular. Director Grupo Investigación Política y Sostenibilidad. Universidad EAN. E - mail: ndiaz@universidadean.edu.co

${ }^{3}$ Doctoranda en Administración. Magíster gestión organizaciones. Coach Ejecutivo Certificado. Docente catedrática, Universidad EAN. E - mail: jalo2000_co@yahoo.com

${ }^{4}$ Magíster en Mercadeo. Politólogo. E - mail: castanoq@gmail.com
} 


\title{
Resumen
}

En este artículo de reflexión que pretende analizar las variables que pueden influir en la confianza en organizaciones sostenibles. Para desarrollar el trabajo se aplicaron estrategias cualitativas, tomando como punto de partida estudios y marcos conceptuales previos realizados. Entre los estudios previos se investigaron temas como liderazgo, transparencia, tipos de confianza, construcción de confianza, sostenibilidad, entre otros.

A partir del estudio se profundiza la manera como, a partir de diferentes factores, generadores de confianza o de sostenibilidad, se puede identificar, crear, medir, y cuantificar índices de confianza dentro de las organizaciones. Así mismo, teniendo en cuenta estas mismas variables, se evalúa la relación entre la confianza y el desempeño organizacional por medio del análisis del recurso humano como un elemento de coordinación en la ejecución de las diversas tareas de la organización.

Palabras clave: Confianza, sostenibilidad, organizaciones, desempeño, empresa.

\section{Implication of confidence in business sustainability}

\begin{abstract}
This reflective article, presents an analysis of the factors that influence trust in sustainable organizations. The strategies used to develop the article, were mainly qualitative ones, taking as it's starting point previous studies and conceptual frameworks made. Among previous studies, it was researched different topics such as leadership, transparency, types of trust, trust building, sustainability, among others.

The conclusion of this study, is that, from different factors, generators of trust or sustainability creation of trust in organizations, can be achieved. Also, with the same factors, and the same proportions of those, two or more different companies can be established through the different human resources in them.
\end{abstract}

Key words: trust, sustainability, organizations, performance, business. 


\section{Implicação da confiança em a sostenibilidade empresarial}

\section{Resumo}

En este artigo se pretende analizar as variáveis que podem influenciar a confiança nas organizações sustentáveis. Para o desenvolvimento do trabalho se aplicam estratégias qualitativas, tendo como ponto de partida estudos e marcos conceptuais previos realizados. Entre os estudos prevê se investigar os temas como liderazgo, transparência, tipos de confiança, construção de confiança, sustentabilidade, entre outros.

A partir do estudo se aprofunda a forma como, a partir de diferentes fatores, geradores de confiança e de apoio, pode se identificar, criar, medir e cuantificar índices de confiança dentro das organizações. Assim mesmo, tendo em conta as mesmas variáveis, se evalúa a relação entre a confiança eo desempenho organizacional pelo meio de análise do recurso humano como um elemento de coordenação na execução das diversas tarefas da organização.

Palavras chave: Confianza, sostenibilidad, organizaciones, desempeño, empresa.

\section{Introducción}

En las condiciones empresariales actuales, no es un secreto que las organizaciones necesitan fijar una orientación proactiva hacia la confianza como el pilar de toda interacción interpersonal exitosa. Los grupos de interés deberían concebir la confianza organizacional como ese pegamento que los une con los líderes y gestores de las empresas, de tal manera que la confianza se convierta en una combinación efectiva de credibilidad, compromiso y ética. Este factor debe ser gestionado de forma acertada, pues de lo contrario puede generar problemas que arriesguen la efectividad de las operaciones, así como la misma existencia de la organización, relacionados con la transparencia, el liderazgo, o la reputación en el sector económico.

Bajo esta premisa, es fundamental reconocer que nos encontramos en un mercado dinámico y cambiante, caracterizado por nuevas tendencias que obligan a las empresas a abandonar prácticas de control y predicción, en la cual demuestren estilos gerenciales mucho más legibles y vinculados con las nuevas tendencias. Por tal motivo, la sostenibilidad empresarial surge como respuesta a los nuevos retos que impone el contexto, se apoya en la innovación, en nuevas tecnologías y transforma la mentalidad de todos los grupos de interés. Las empresas de hoy deben crear valor diferencial, contar con empleados satisfechos, comprometidos y capacitados; contar con flexibilidad operacional, así como contar con procesos 
innovadores para dar respuestas efectivas a los problemas sociales y a las necesidades de los clientes.

En ese sentido, aunque existen investigaciones, no es posible encontrar estudios avanzados sobre cómo lograr que la confianza sea la piedra angular para construir organizaciones sostenibles. El PRIME Business School de la Universidad Sergio Arboleda sostiene que las organizaciones, como entes construidos por seres humanos, necesitan integrar, conversar y realizar acciones coherentes con una dirección estratégica compartida. Es decir que todos los actores interesados deben mantener su propia autonomía, donde puedan distinguir que tienen más de una acción viable a la mano y que su preferencia de acción es legítima, donde puedan emerger diferentes posturas y todas son incluidas para lograr acciones compartidas. Para todo lo anterior, la confianza es la condición que posibilita el éxito de los elementos descritos previamente.

Citando a la revista Portafolio (2015).

En concreto, entonces, la gerencia contemporánea debe estar dispuesta a mantener y promover espacios de confianza; lo que representa un reto de transformación de las relaciones cotidianas, así como de la lógica gerencial: desde la manera en la que se diseña un proyecto hasta el modo de ejecutarlo y evaluarlo; desde la forma en que se saluda, hasta el modo en el que se reparten las tareas y responsabilidades. En últimas, es ejercer una forma de liderazgo que no esté basada en el ejercicio del poder ni en la competencia sino en la capacidad de inspirar alianzas, en aras de facilitar y acompañar procesos asociativos, creativos y de trabajo continuo. Solo en el momento en el que todos: clientes, empleados, proveedores, se sientan en un espacio de confianza en la empresa, se podrá afirmar que es sostenible. (Pág. 1).

\section{Marco Teórico}

Alrededor del concepto de confianza se han desarrollado diversas teorías. Kee y Knox (2004), por ejemplo, describen las situaciones de confianza como aquellas donde las partes participantes saben que los resultados de sus opciones son mutuamente dependientes. Así, si uno de los actores decide no confiar, deja a los otros sin posibilidades de acción, fueran estas últimas legítimas o no. La confianza, entendida de esta manera, es necesaria no solo para la consecución del crecimiento económico, a partir del fortalecimiento de las relaciones entre empresas, proveedores y clientes, sino también para el adecuado funcionamiento de las relaciones internas. De manera similar, la instauración de prácticas empresariales sostenibles, contribuye a partir de la transparencia y la ética al desarrollo de la confianza. 
Russel Hardin (2002) ofrece otra perspectiva sobre el tema: define la confianza a través del interés encapsulado, bajo la hipótesis de que la parte confiada tiene el incentivo de ser confiable. De este modo, las relaciones se prolongan y estrechan a partir de la existencia de incentivos que beneficien a ambas partes. Cabe aclarar que en el contexto organizacional los beneficios o incentivos pueden ser económicos o de otra índole y están basados en interacciones menores, si estas se comparan, por ejemplo, con aquellas que se dan en las relaciones familiares o personales. Este enfoque permite entender cómo la confianza entre la sociedad y las organizaciones es fundamental para el desarrollo de la sostenibilidad empresarial: la interdependencia indicada por Lozano (2012) al citar al CEC (comisión de las comunidades europeas) y a Elkington, entre los aspectos sociales, ecológicos y económicos de las empresas y su entorno, genera un incentivo tanto para la sociedad como para las corporaciones, donde ambas buscan, en última instancia, beneficiarse mutuamente.

Mayol (2007), al realizar una conceptualización acerca del tema, recurre a Schlemenson, para quien la confianza entre otras cosas lleva a "fortalecer lazos de colaboración que llevan a consolidar las relaciones sociales y la construcción de un objetivo social compartido" (p. 45) y a Bastons i Prats, quien considera que:

Es un sentimiento que se tiene respecto a las intenciones de un agente, que surge del convencimiento de que su sistema de control internaliza (evalúa) los resultados implícitos de las acciones y hace sensible al agente a «lo que le pasa al otro» en la interacción con él (p.45).

Bajo estas perspectivas, es evidente cómo la confianza y la sostenibilidad empresarial se realimentan mutuamente: mientras la confianza entendida desde la formulación de Prats requiere de las empresas que evalúen las potenciales consecuencias de sus acciones y adopten prácticas de sostenibilidad, la instauración de este tipo de prácticas ciertamente fortalece los lazos de colaboración y ayuda a consolidar las relaciones entre los grupos de interés y las organizaciones, promoviendo la confianza entendida desde el punto de vista de Schlemenson.

Lewis y Weigert (1985), desde un marco sociológico, consideran que la confianza ...existe en un sistema social siempre y cuando los miembros de ese sistema actúen de acuerdo y se sientan seguros con el futuro esperado, constituido por la presencia de cada uno o su representación simbólica (p.968).

En este sentido, la sostenibilidad empresarial garantizaría la confianza entre las corporaciones, sus colaboradores y sus grupos de interés, ya que ciertamente el tipo de prácticas que conlleva requiere que las organizaciones actúen de acuerdo 
a principios que constituyen beneficios para estos. Estos autores recalcan que, "aunque la confianza es fundamental para las relaciones sociales, siempre involucra un inevitable elemento de riesgo y duda potencial" (p.968).

Cooper (1998) por su parte, considera que la autoconfianza es un pilar sobre el que se erige la confianza hacia otras personas u organizaciones:

Cuando confiamos en nosotros mismos y podemos extender esa confianza a los demás y recibirla de regreso, esta se convierte en el lubricante que mantiene unidas las relaciones y libera la confiabilidad. La falta de confianza, por el contrario, nos hace gastar tanto tiempo en protección, dudas, verificaciones e inspecciones como en hacer trabajo real, trabajo colaborativo, de creación, que agregue valor a la organización (p. 395).

De esta manera, las empresas deben crear una relación de confianza con sus colaboradores para luego poder extenderla a sus grupos de interés. En la construcción de la sostenibilidad empresarial esto tiene que ver con la ética al interior de las corporaciones, el intercambio oportuno de información entre departamentos e individuos, y especialmente en la instauración de prácticas de gobierno corporativo, que promueven el manejo adecuado y eficiente de los recursos al interior de la empresa, de manera que esto se evidencie en la generación de beneficios para los grupos de interés (Epstein y Buhovac, 2014).

Rousseau, Sitkin, Burt y Camerer (1998), en un esfuerzo por crear una definición de confianza aceptable para diferentes disciplinas como la psicología, la sociología y la filosofía (entre otras), la describen como "un estado psicológico que incluye la disposición a aceptar vulnerabilidad, fundamentado en expectativas favorables de las intenciones o comportamientos de otros". En la actualidad las dinámicas entre las organizaciones y su entorno exigen que ambas partes acepten cierto nivel de vulnerabilidad hacia la otra: las acciones de las empresas repercuten en la sociedad y los grupos de interés pueden dificultar el desarrollo corporativo. La aceptación de la vulnerabilidad únicamente se da cuando las partes están convencidas de que no hay una disposición para dañarse mutuamente. La sostenibilidad empresarial permite que exista cierto nivel de seguridad en los grupos de interés acerca de la buena fe de las empresas.

Topa, Palací y Morales (2004) retomaron el concepto ofrecido por los tres autores mencionados anteriormente, y resaltaron la importancia de la confianza para el éxito de las organizaciones. También citaron a Lanschinger, Finegan y Shamian, quienes consideran que las personas no podrían trabajar juntas sin confianza, a menos que los procedimientos de control fuera extremos. Por esto, es importante que las organizaciones cultiven la confianza interna y externamente, si buscan la consecución eficiente de sus objetivos. De este modo, el desarrollo de confianza 
contribuye a la generación de valor para la empresa y a la construcción de una relación más cercana con los actores externos, de la cual depende el éxito organizacional, lo que impulsa el desarrollo de la sostenibilidad.

Kramer (1999) cita a Robinson, quien define la confianza como las expectativas o creencias de que las acciones de otros serán beneficiosas, favorables o por lo menos no dañinas con respecto a los intereses propios. Por este motivo, la sostenibilidad permite que la confianza de los grupos de interés hacia las organizaciones crezca, ya que las empresas que la instauran muestran interés en la consecución de sus objetivos a partir de acciones con consecuencias beneficiosas para la sociedad.

Solomon y Flores (2001), citados por Starnes, Truhon y McCarthy (2010), clasifican la confianza en básica, simple, ciega y autentica. 
Tabla 1: Tipos y características de la confianza.

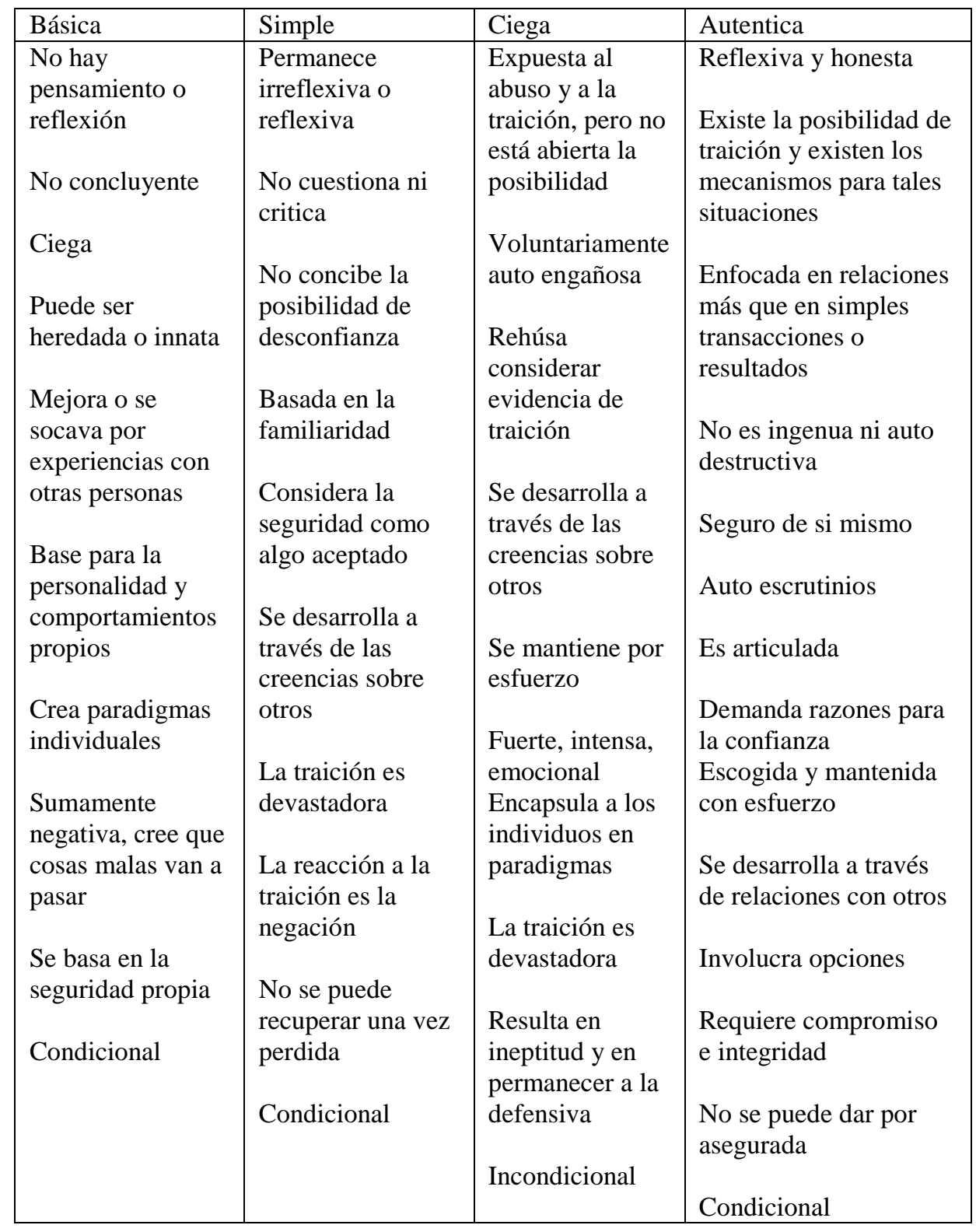

Fuente: A primer on Organizational trust (2010) de Becky Starnes, Stephen Truthon y Vikkie McCarthy realizado para ASQ (Milwaukke, Estados Unidos). 
Entre las definiciones que dan los autores, la confianza básica es la capacidad y la voluntad de conocer gente sin sospechas desmesuradas, la capacidad de hablar y tratar con extraños, y la disposición a entrar en las relaciones íntimas. Este tipo de confianza proporciona la base para la personalidad y actitud de las personas hacia el mundo. Entretanto, La confianza simple es la ausencia absoluta de sospecha: no exige reflexión, elección consciente, control y justificación. Puede ocurrir debido a que jamás ha surgido algo para cuestionar la fiabilidad de la otra persona, pero puede también ser debido a que se es ingenuo.

La confianza ciega ha sido expuesta a la violación y la traición, pero se niega a creer que se ha producido. La confianza ciega niega la posibilidad de que cualquier cosa pueda sacudir o traicionar la confianza. Mientras que la confianza auténtica es totalmente consciente de sí misma, consciente de sus propias condiciones y limitaciones, abierta a nuevas e incluso inimaginables posibilidades, sobre la base de la elección y la responsabilidad en lugar de las operaciones mecánicas de la previsibilidad, la dependencia y rigidez. La confianza auténtica es muy consciente de los riesgos y dispuesto a enfrentar la desconfianza y a superarla.

En el contexto empresarial, la confianza ha sido estudiada desde diferentes perspectivas, y se ha analizado su impacto dentro y fuera de las organizaciones. Así, Arrow (1971) define la confianza como un lubricante esencial sin el cual las más simples formas de intercambio económico no podrían ocurrir. Desde este enfoque, la confianza es deseable porque incrementa la eficiencia de los intercambios, generando gastos menores en aspectos relacionados con el control que las empresas realizan sobre las transacciones comerciales. Esta definición se encuentra relacionada estrechamente con el concepto de confiabilidad, donde el cumplimiento de los compromisos es de extrema importancia para el desarrollo de las relaciones comerciales.

Para la generación de confianza empresa - empleados, Illes y Mathews (2015) consideran que existen cinco factores importantes para generar confianza de los empleados hacia la empresa. El primer factor es la estabilidad laboral (no despido por causas ajenas al desempeño laboral). Otro factor importante es la evaluación del desempeño (como se realizaron las tareas propuestas y la asignación de nuevos compromisos entre empleado y empleador). El entrenamiento y capacitaciones son importantes debido a que la empresa le dice al empleado "queremos que se quede y vamos a mejorar sus capacidades laborales". Un cuarto factor es la justicia procedimental, que busca generar legitimidad e integridad en todos los procesos de selección o de resolución de conflictos en las compañías. Un último factor se basa en la justicia distributiva que busca que los salarios, bonos y cuestiones de despidos o capacitaciones sean apegados a la realidad.

Volumen XVI (1) (Enero - Diciembre 2016). ISSN 0121 - 1048 
Coincidiendo con Illes y Mathews (2015), Jennifer Schramm (2015) en el artículo "Respect and trust top to the list of most important employee job satisfation Factors" publicado en el blog de SHRM (Society for Human Resource Management), explica que el entrenamiento y la oportunidad de ascender en las empresas es un factor que genera respecto y confianza en las organizaciones y en consecuencia satisfacción e implicación en el trabajo. El 72\% de los encuestados dijeron que las relaciones respetuosas entre todos los empleados eran muy importantes y el $64 \%$ argumentaron que la confianza entre los empleados y los directivos es muy importante.

Amy Anderson (2013) en su artículo "Good Employees make mistakes, Great leaders allow them to" publicado en la revista Forbes, explica que los errores son una forma de conseguir nuevas ideas e innovación y que no son fracasos sino un proceso donde se eliminan alternativas que no funcionan a un problema. Los buenos empleados son aquellos que aprenden de los errores, los dominan, los arreglan y ponen seguros para que el error no se vuelva a cometer. Otro punto importante es que no en todas las áreas se puede experimentar con los errores por lo que se debe escoger que divisiones de una empresa pueden equivocarse.

En cuanto a la importancia de la comunicación en las organizaciones, en el blog de Projection Central (2014) argumentan que la comunicación en una empresa es importante dado que todos necesitan saber lo que ocurre con un proyecto en todo momento. Existen tres formas de comunicación efectiva en las empresas. La primera es la comunicación Bottom-Up, que significa comunicarse con jefes inmediatos, ejecutivos u otros grupos interesados en el proyecto. Se debe buscar que los mensajes orientados sean breves y sustanciosos para que se entiendan y se pueda realizar los correctivos necesarios.

La segunda forma de comunicación es Top-Down, donde las personas que trabajan en el proyecto no siempre son subordinados del gerente del proyecto. Esto significa que la comunicación debe ser clara y concisa debido a las presiones que tienen por medio de su jefe inmediato o de otros gerentes de proyectos. Por lo tanto, las estrategias para que la información llegue pueden incluir reuniones semanales, conversaciones 1 a 1 o documentación actualizada del proyecto. Finalmente, la comunicación horizontal es necesaria debido a que se necesitan recursos de otras áreas. La mejor manera de hacer esa comunicación real es el relacionamiento en actividades conocer los diferentes puntos de vista de las personas y generan empatía entre colegas.

Marta Lucia Restrepo (2007) en su artículo "Construir la confianza, un verdadero arte" publicado en la revista LatinPyme argumenta que la construcción de la confianza en una organización debe seguir cinco puntos. 
Figura 1: Confianza en la organización.

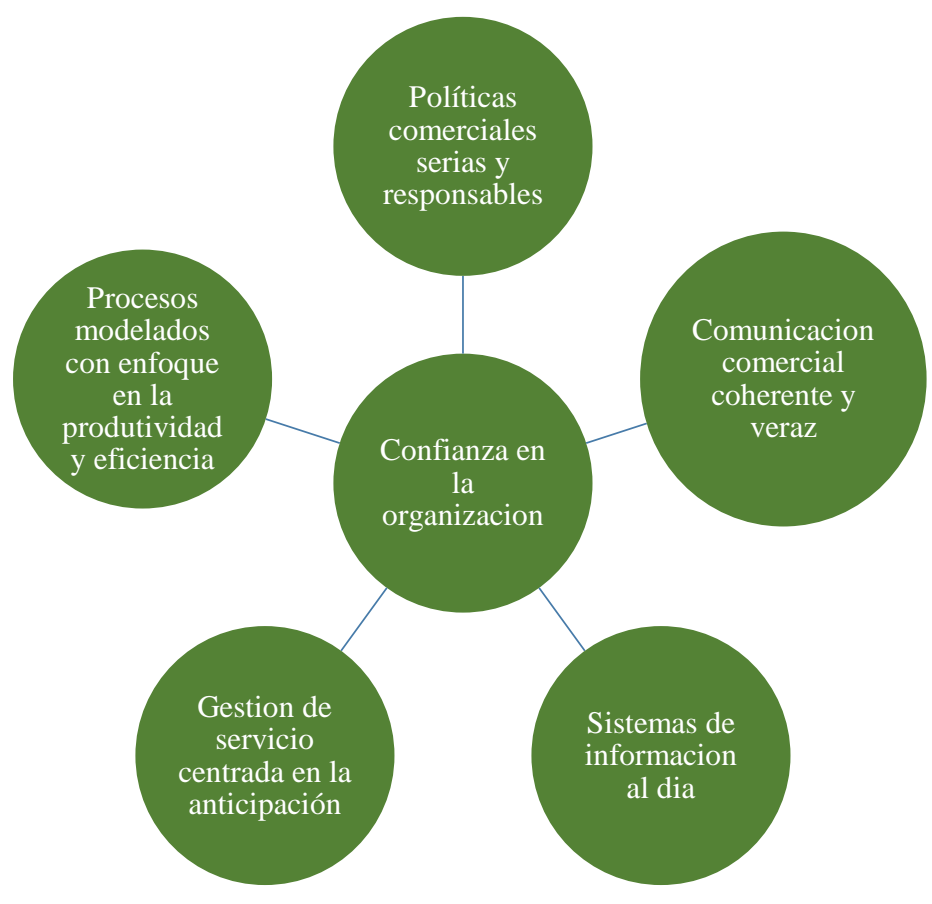

Fuente: Elaboración propia con datos del artículo "Construir la confianza, un verdadero arte" publicado en la revista LatinPyme (2007).

Las políticas comerciales serias y responsables, generan sentido de pertenencia y claridad sobre las reglas de juego. La organización se debe centrar sobre la claridad de las políticas y los procesos para actuar en la prestación del servicio. La política comercial debe ser: amplia y suficiente, flexible y concreta, específica en su alcance, funcional en su aplicación y clara en su expresión (verbal o escrita).

En cuanto a la comunicación comercial coherente y veraz debe existir un flujo de ida y vuelta con los diferentes grupos de interés. Se debe realizar un esfuerzo por decir las cosas como son, lo que provocará beneficios y aumentará el prestigio y confianza en su organización. La comunicación debe ser anticipada, previendo preguntas y estructurando respuestas que sean oportunas y útiles para sus públicos. Se debe utilizar la comunicación comercial para crear una experiencia clara, transparente y de mutuo beneficio. Además, debe ser: objetiva y oportuna, veraz, ética, comprensible a todos los públicos y transparente en todos los sentidos, especialmente en el jurídico. 
Un sistema de información debe servir para contextualizar la realidad de la organización en su sector económico. Además, debe permitir combinar la información que se tiene de los clientes con las formas de comunicación hacia los mismos. Las características de un sistema de información eficiente son: Estar al alcance de todos, operar de manera óptima, proveer suficiente información, estar soportado por tecnología y que sea administrado todos los días por expertos.

En cuanto a la gestión del servicio centrada en la anticipación, la confianza está relacionada con el servicio como valor de la organización. Debido a que es un desafío a la capacidad de respuesta de la institución y a las expectativas del cliente, la gestión del servicio es la llave del éxito porque la calidad de la experiencia compromete y estimula la preferencia de los consumidores. La gestión del servicio tiene las siguientes características: Manejo de expertos en los procesos, Empoderamiento de los equipos de frente al comprador, Mediciones personalizadas y anticipación a la dinámica comercial.

Finalmente, los procesos modelados con enfoque en la productividad y eficiencia se refieren a la confianza de hacer las cosas bien. El pensamiento por procesos se da en organizaciones con grados de reflexión seria y disciplinada. Esto permite sostener las promesas comerciales e internas e identificar oportunidades de mejora. Entre las principales características técnicas de estos procesos se encuentran: revisión permanente de cada proceso relacionado con el cliente, entrenamiento de los equipos de trabajo en el proceso, mejoramiento continuo y análisis de casos, sucesos y hechos puntuales para aprender de ellos.

En el tema de liderazgo organizacional, Victor Buzzota (2001) explica a través de su Modelo de Comportamiento Dimensional los diferentes tipos de liderazgo para generar una cultura de confianza en las empresas. 
Figura 2: Modelo de comportamiento dimensional.

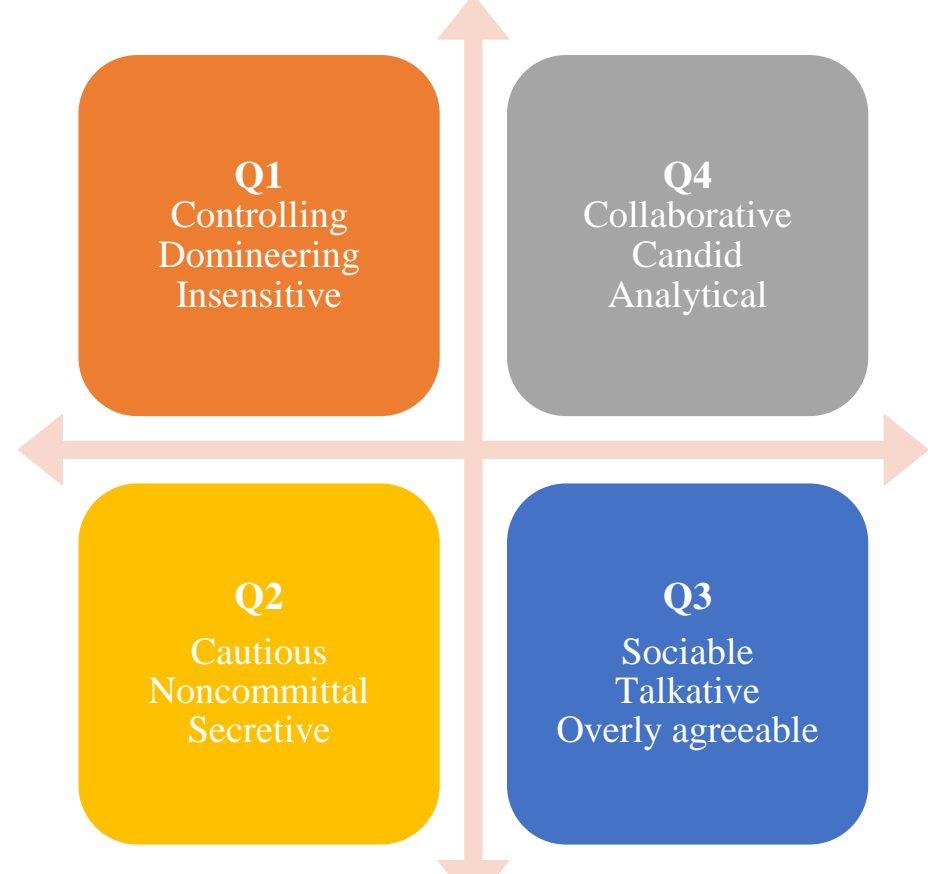

Fuente: Documento encontrado en Communicare. El título es "Trust as a style" escrito por Víctor Buzzota (2001, p. 2).

El estilo de liderazgo en Q1 combina comportamientos hostiles y dominantes. Los comportamientos tienden a ser controladores e insensibles. Con este tipo de liderazgo no se genera confianza debido a que la persona realiza su trabajo por interés propio, lo que dificulta la generación de trabajo en equipo y de relaciones de trabajo.

En Q2, la confianza no se puede crear debido a los comportamientos del estilo de liderazgo en Q2 son cautelosos, no comprometidos y reservados. Lo anterior ocasiona que se disminuya el riesgo operacional de la empresa, pero no genera un ambiente adecuado para confiar en los empleados.

El estilo de liderazgo de Q3 está enfocado en agradar a otras personas. Los comportamientos observados son de personas altamente sociables, habladoras y agradables. El problema con este tipo de liderazgo es que las conversaciones no son profundas. La debilidad que tienen para tomar cualquier decisión, ya sea porque aplaude todo y que las decisiones tomadas siempre buscan ser populares, 
aunque la compañía no pueda soportarlas, hacen que este tipo de líder sea poco fiable.

Solamente, los líderes en Q4 inspiran confianza. Esto se debe a que son personas sinceras, colaborativas y analíticas, lo que hace que acepten el riesgo de confiar en otros. En cuanto a las habilidades que desea que sus empleados tengan, las más importantes son el empoderamiento y la colaboración entre todos. El líder demuestra confianza en cada una de sus actividades mientras anima a las personas a confiar los unos con los otros.

En cuanto a la transparencia de los líderes empresariales, Glenn Llopis (2012) en su artículo "5 Powerful things happen when a leader is transparent" publicado en la revista Forbes, argumenta que los empleados quieren que sus líderes sean más humanos, menos perfectos y algunas veces vulnerables. Esto se debe a que las personas necesitan que los directivos sean transparentes en sus actuaciones ante ellos y por lo tanto desean ver al líder como alguien que ha superado los mismos obstáculos que ellos tienen.

Los cinco resultados de tener un líder transparente son:

1. Los problemas se resuelven más rápido

La transparencia lleva a que los equipos de trabajo puedan descubrir soluciones en menos tiempo y evitando algunas soluciones drásticas (recorte del presupuesto) a problemas como líneas de rendimiento mínimas.

2. Los equipos se construyen fácilmente

Esto se debe a que las personas son asignadas a las funciones que se consideran más factibles dadas sus fortalezas y debilidades en su ingreso al equipo de trabajo. Además, cultiva un espíritu emprendedor para el intercambio de responsabilidades y de oportunidades de crecimiento profesional.

3. Relaciones interpersonales autenticas

Las relaciones interpersonales maduran de una manera acelerada cuando las personas pueden confiar en otras y sus rasgos de personalidad se complementan. Además, que el estar abierto a nuevas relaciones interpersonales puede evitar malentendidos que generen tensión e un equipo de trabajo. 
4. Personas empiezan a promover la confianza en su líder

Las personas son más objetivas acerca de las ventajas y desventajas de sus líderes y en momentos de crisis tu liderazgo se incrementa y las personas confiaran en usted como persona y por ende como líder. También se promoverá su liderazgo con personas ajenas a su equipo eliminando prejuicios que se tengan.

5. Los niveles de rendimiento aumentan

Todos los puntos anteriores se deben cumplir para poder tener niveles de rendimiento altos dado que el único que pierde con no ser transparente es el líder debido a que las personas no darán su máximo potencial de rendimiento si su líder esconde información acerca de los proyectos.

Tan y Lim (2009) consideran que, al interior de las organizaciones, la percepción de las habilidades, benevolencia e integridad de los colaboradores constituyen la base de la confianza. Cuando la sostenibilidad se cultiva al interior de las empresas, se cultivan también la integridad y la benevolencia de los colaboradores.

Por otra parte, Stephen Robbins (2004) considera que la confianza es "la esperanza positiva de que otra persona no se conducirá de forma oportunista por medio de palabras, obras o decisiones", donde el oportunismo puede entenderse como búsqueda de los intereses propios. La conducta oportunista de grandes corporaciones ha afectado la economía, el medio ambiente y la sociedad de distintos países; la de algunos directivos ha llevado compañías enteras a la quiebra. Las prácticas de sostenibilidad empresarial buscan desincentivar el oportunismo, no a partir de mecanismos de control más estrictos, sino a partir de cambios de fondo en la cultura organizacional y en los procedimientos normales de las empresas. Por esto, la sostenibilidad ayuda a promover el desarrollo de la confianza entre los grupos de interés y las organizaciones.

Almeida (2009) considera que la comunicación y la transparencia crean confianza, ya que permiten apreciar la integridad de cada una de las partes. Según la autora, la información comunicada no debe limitarse solo a la económica o financiera, sino que además debe incluir toda la información relevante para los diferentes grupos de interés. Estos dos factores también son importantes para el desarrollo de la sostenibilidad, como fue explicado por Epstein y Buhovac. De esta manera, el crecimiento de la confianza está ligado al desarrollo de la sostenibilidad, pues ambas dependen de factores comunes para su mejoramiento. 
Hernández, A. M. (2010) establece las ventajas que entraña para una organización el desarrollo de la confianza: la primera está relacionada con la eliminación o reducción de mecanismos de control y la burocracia, y por lo tanto, con la reducción de los costos; la segunda se relaciona con la transferencia de información y conocimiento, que se realiza más oportunamente y permite asumir riesgos de una manera más adecuada; la tercera hace referencia a la motivación de los colaboradores, que aumenta gracias a la disminución de los mecanismos de control y les brinda una mayor autonomía; la cuarta y última se refiere a la mejora del clima laboral.

Mintzberg (1992) ofrece una perspectiva diferente; para él, la confianza es “...la creencia de que los objetivos sociales también son importantes para los directivos, y por tanto se cuidan de ellos por interés propio, porque es lo correcto, y no por las presiones que puedan recibir.” (p. 677). Así, la confianza podría entenderse de cierta forma, como la creencia de que las empresas aplicarán la sostenibilidad a sus actividades, ya que estas buscan el desarrollo social, económico y ecológico del entorno.

Adicionalmente, este autor sostiene que no se puede confiar en las empresas sin antes presionarlas y regularlas. John Wecker (2002) coincide con Mintzberg en este último aspecto, ya que considera que la confianza no disminuye el requisito de establecer sistemas de control o vigilancia. En este sentido, ambos autores difieren con Arrow, quien considera la eliminación o reducción de los mecanismos de control una de las ventajas más grandes que ofrece la confianza en las relaciones empresariales. Sin embargo, esto puede explicarse a través de la diferencia entre los conceptos de confianza ofrecidos por cada uno de ellos. La perspectiva de Mintzberg exige un comportamiento ético y transparente de la parte confiada, en este caso las empresas (más exactamente los directivos de estas), además de una preocupación por el desarrollo social del entorno. Dado que existe un alto grado de dependencia de las acciones del individuo y de la corporación, es comprensible que estos autores consideren necesario verificar que los principios éticos y los objetivos relacionados con el desarrollo social del individuo se alinean con los de la empresa, y que los de esta están relacionados con los de su entorno.

Por su parte Guillermo Bosovsky (2011) en el artículo "El problema de la credibilidad y la reputación corporativa" de la revista Tiempo de mercadeo, explica que en Europa la tendencia es observar los valores representados por las instituciones y las empresas a través de conceptos como la ética, la responsabilidad, la veracidad, el respeto, la transparencia, la búsqueda de relaciones gana-gana y la sostenibilidad. El autor argumenta que el fracaso de una estrategia comunicativa de reputación corporativa se debe a que está basada en la emisión de mensajes, ambición cortoplacista, presión entre otros factores. 
Debe existir un cambio de paradigma que requiere identificar los puntos de vista de los grupos de interés y confrontarlos con los que existen dentro de la organización para poder establecer relaciones verdaderas con los públicos.

El articulo propone realizar tres niveles de análisis, en un primer momento se debe realizar una valoración de la reputación de la organización en un contexto de organizaciones significativas para la sociedad. Un segundo estudio donde se mida la reputación en su mismo sector económico y preguntando los por qué. Finalmente, una evaluación cuali-cuantitativa de los rasgos de imagen de la organización, incluyendo la forma que los públicos perciben la actitud hacia diferentes temas, la cultura corporativa, entre otros. Con todos estos datos, se puede realizar una estrategia de reputación corporativa, que debe incluir un procedimiento para la comunicación con los distintos grupos de interés y un sistema de seguimiento de los resultados.

De acuerdo a Leon Bracey (2012) en el artículo "The importance of business Reputation" publicado en Business in focus, la reputación de un negocio es esencial para su sobrevivencia. Aunque en el pasado era un tema del cual eran conscientes los grupos de interés a través del "boca a boca", en los últimos años los nuevos medios de comunicación (redes sociales y comunicación instantánea) hacen que las compañías deban estar pendientes de la reputación todo el tiempo y enfrentar cualquier crisis cuando surja. Si la compañía tiene gran reconocimiento y una reputación importante los consumidores van a preferirla sobre otras que ofrecen lo mismo, esto sin importar el precio. Los siguientes consejos pueden ayudar a generar reputación para la compañía.

Figura 3: Consejos para generar reputación.
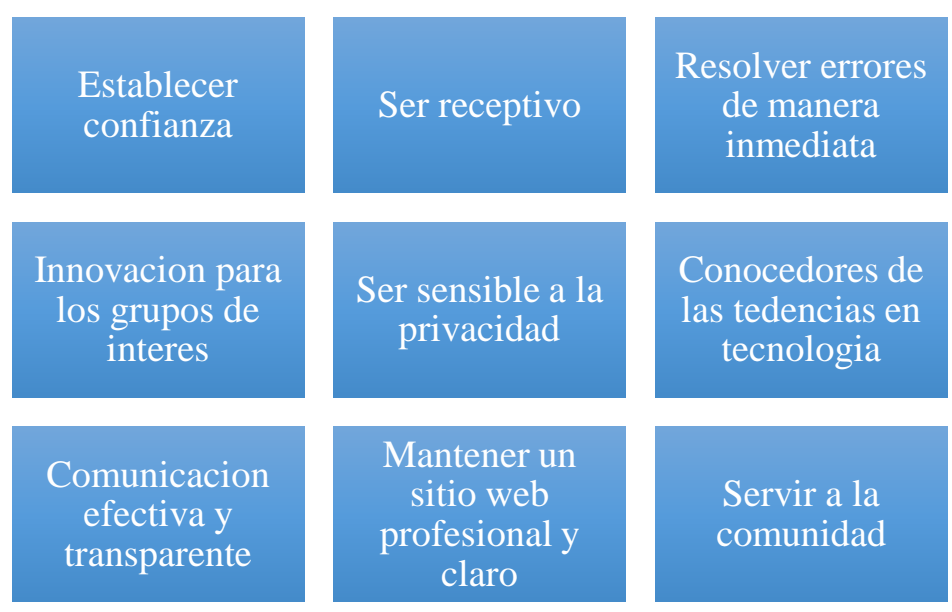

Fuente: Creación propia con datos de Leon Bracey (2012) en el artículo "The imoportance of business Reputation". 
Siguiendo con el tema de reputación empresarial, Harlan Loeb y Eric McNulty (2014) en el artículo "Don't trust your company's reputation to the Quants" publicado en la revista Harvard Business Review, explican que el riesgo de la reputación es cualitativo y cuantitativo y que los riesgos que una empresa enfrenta deben tener soluciones diferentes a las operativas y financieras. Se menciona el indicador de Harris Interactive team que tiene 6 macro indicadores.

Figura 4: Harris Interactive Team - Macro indicadores.
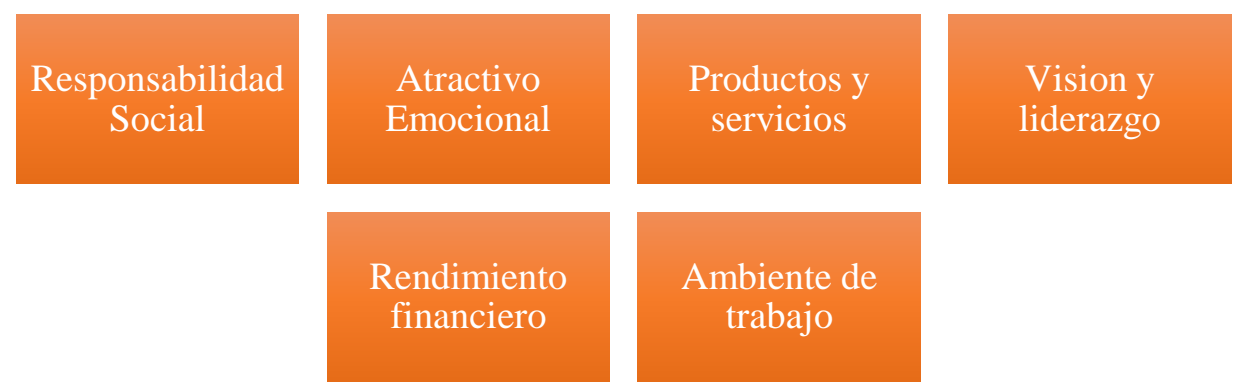

Fuente: Creacion propia con datos de Harlan Loeb y Eric McNulty (2014) en el artículo "Don't trust your company's reputation to the Quants".

Según el último informe de este indicador, mencionado en el artículo, las primeras 10 compañias son empresas de distribución de productos donde el consumidor tiene un papel relevante (ej. Coca-Cola, Walmart, Whole Foods) y las ultimas 10 son empresas que los consumidores conocen solo por reputación y nombre (ej. Goldman Sachs, AIG, Monsanto). Las personas que trabajan en análisis cualitativo, los qualts, deben ser escuchadas dado que tienen una visión enfocada en las relaciones que se forman con los distintos grupos de interés y como resultaran afectados. Estas personas pueden ser de ayuda en tiempos de crisis y reconstrucción de la compañía para conseguir que la empresa permanezca relevante. Esto se debe a que se analizan valores y emociones y se diseñan estrategias para generar valor y empatía con la empresa.

En el tema de generación de confianza empresa-cliente, Melissa Schaefer en su artículo "Como ganarse a un consumidor cada vez más poderoso" publicado en la revista América Empresarial (2013) explica que la confianza de los consumidores en los distribuidores de productos al por menor se da en los mercados o tiendas de barrio en donde el conocimiento de las preferencias y necesidades de los clientes son conocidos. De acuerdo con Sandro Castaldo, colaborador del estudio, la confianza en comercio al dedal se da por tres factores: la experiencia de compra, la experiencia del producto y las comunicaciones. $\mathrm{Si}$ hay suficiente confianza entre clientes y distribuidores, los primeros pasan a ser partidarios. Lo anterior conduce a un mayor gasto y conduce a ser la primera 
opción cuando nace una necesidad relacionada con el sector del distribuidor. (citado por Schaefer, 2013, p. 3).

Castaldo argumenta que los empleados deben conocer las preferencias y necesidades de los clientes para poder ayudar y asesorar a los clientes. Toda la información que permita al cliente satisfacer su necesidad de compra debe ser puesta a disposición del mismo. Por ejemplo, si un producto también se vende en línea, el empleado debe contar con la misma información que esta descrita en el sitio web. En síntesis, los empleados deben ser embajadores de las marcas. (Citado por Schaefer, 2013, p. 3).

En cuanto a nuevas estructuras empresariales, Paul Adler en el artículo "Como construir una empresa Colaborativa" de la revista Harvard Business Review (2011) muestra una nueva estructura de empresa, llamada comunidad colaborativa que requiere cuatro iniciativas organizacionales para poder ser implementada.

Figura 5: Harris Interactive Team - Macro indicadores.
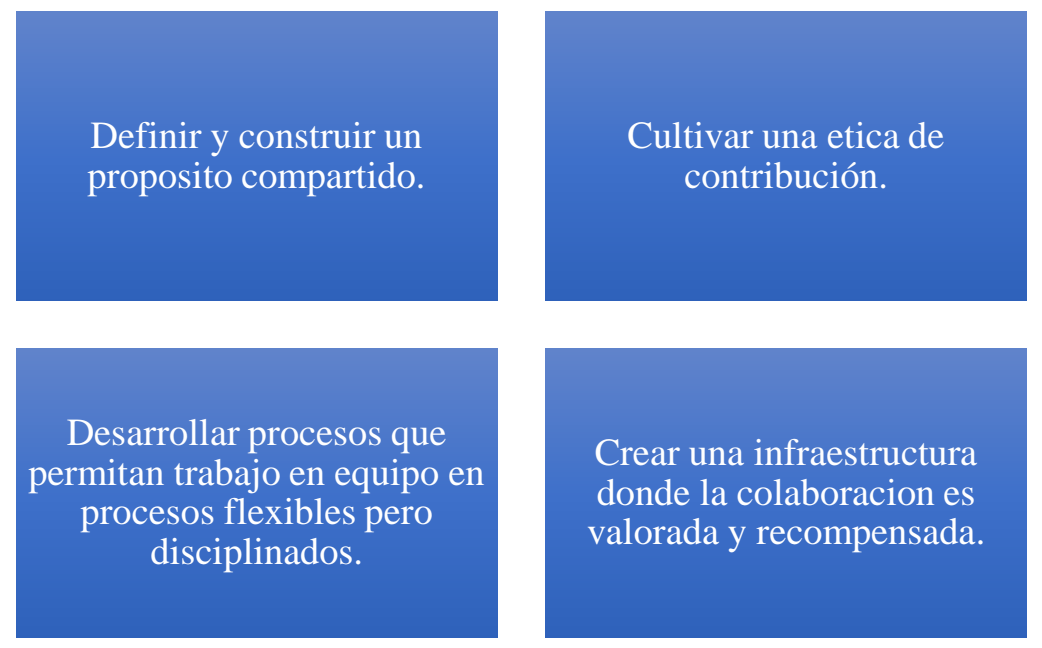

Fuente: Creación propia con base en el artículo "Como construir una empresa colaborativa" de la revista Harvard Business Review.

Un propósito compartido es la forma como una empresa o grupo empresarial se posiciona de acuerdo a los competidores, socios y las contribuciones que los clientes y la sociedad usaran para definir su éxito. Es multidimensional, practico y constantemente se enriquece en debates sobre problemas concretos.

La construcción de una ética de contribución inicia con un conjunto de valores distintivos que se comparten. Se valora en este tipo de ética el ayudar al propósito común. Se enfatiza el trabajo en equipo y los mejores aportes de cada individuo 
para el bien común. La confianza generada con la ética de la contribución es menos natural que en las organizaciones tradicionales debido a que en estas últimas las señales simbólicas de la cultura compartida (por ejemplo, los bonos por ser buen empleado) generan un fuerte arraigo en las personas. Pero es menos voluble que la confianza construida a partir de la fe en un líder carismático y en las deslumbrantes exhibiciones de la brillantez individual.

Para que las personas puedan contribuir entre sí, se necesita crear un mecanismo llamado gestión de procesos interdependientes, un grupo de técnicas que incluye el kaizen, el mapa de procesos y protocolos formales para el brainstorming, gestión de reuniones participativas y toma de decisiones con varios stakeholders. Se debe informar a todos los participantes del proyecto los cambios hechos al proyecto debido a que todos tienen que entenderlos.

La unificación de los aspectos anteriores se realiza a través de una estructura de autoridad que se denomina centralización participativa. Participativa, debido a que moviliza el conocimiento de todos y centralizada porque ese conocimiento debe ser coordinado de modo que se pueda usar en distintos proyectos.

La estructura usual en las empresas colaborativas es la estructuración por matrices donde las personas no pertenecen a áreas sino a proyectos. Son altamente difíciles de mantener, pero al mantenerlas las empresas generan ventajas competitivas en sus sectores. Los sistemas de compensación no son los principales motivadores de este tipo de empresas sin que la satisfacción laboral estará determinada por asumir nuevos desafíos dentro de las empresas. Los sistemas de reputación son importantes debido a que se convertirán en la base de selección para los nuevos proyectos.

La confianza, entre otros factores, juega un papel fundamental para que la instauración de la sostenibilidad en las organizaciones sea posible. Así mismo, un enfoque de sostenibilidad contribuye a la construcción de la confianza en una empresa, tanto internamente como en relación con sus grupos de interés.

Por consiguiente; existe un enfoque relacional planteado por Donati y Ruiz, 2006, citado en Márquez 2013 p. 119) el cual se basa en tres semánticas que describen los tipos de relaciones sociales: la semántica referencial o simbólica, que corresponde a asignar el significado o intención de una situación o persona a otra; la semántica estructural o de generación de vínculos que corresponde a la creación de un vínculo que es a su vez un recurso; y la semántica generativa, que se refiere a las relaciones propiamente dichas es la que representa a aquello que se genera entre los sujetos y agentes que están en contacto o tienen un vínculo. Así mismo; Alain Degenne (2009) define las relaciones como un conjunto de interacciones que se presentan entre los mismos individuos a lo largo del tiempo, y a las interacciones como intercambios de corta duración entre los involucrados 
y que son aceptados por todos ellos. Por lo tanto, la confianza influye en la forma en que las personas se relacionan y la manera en que sus actividades colectivas se llevan a cabo, ésta es un componente esencial en el desarrollo da la sostenibilidad empresarial.

\section{Sostenibilidad}

La sostenibilidad empresarial se deriva del concepto de desarrollo sostenible, una de cuyas primeras apariciones se dio en 1987, en el reporte Brundtland Our Common Future (citado por Kurzrok y Hund, 2013). En ese documento se define desarrollo sostenible como "aquel que satisface las necesidades del presente sin comprometer la capacidad de las generaciones futuras de satisfacer sus propias necesidades".

La sostenibilidad se ha convertido en una de las más grandes preocupaciones de la sociedad actual, y esto se ha visto reflejado en las políticas internacionales establecidas por diferentes organismos supranacionales como la ONU y la OEA. Sin embargo, esta no se puede alcanzar sin un esfuerzo conjunto de todos los actores involucrados en el desarrollo de las comunidades.

Las organizaciones juegan un papel fundamental en la preservación de los recursos para las generaciones venideras. Sin embargo, la sostenibilidad empresarial no se limita a este aspecto: busca "conciliar el crecimiento económico con el cuidado del entorno social y la protección del medio ambiente" (Gil, A. M. y Paula, L., 2001, p. 80). Por lo tanto, en el mundo empresarial, la sostenibilidad no está enfocada únicamente a la preservación del medio ambiente, sino que busca el crecimiento económico y social alrededor de las actividades desarrolladas en el entorno de los negocios.

Uno de los primeros autores en integrar el concepto de sostenibilidad al mundo empresarial fue John Elkington (1997, citado en Pinillos y Fernández 2011, p.13), quien sostiene que "para que una empresa sea sostenible, tiene que garantizar un triple objetivo: ser económicamente viable, ser socialmente beneficiosa y ser ambientalmente responsable." Esta definición, que integra el concepto de triple balance o triple cuenta de resultados, evidencia nuevamente la necesidad de integrar la responsabilidad ecológica y social a los objetivos económicos de las organizaciones.

Para la dimensión económica de la sostenibilidad, la consultora McKinsey (2011) nos ofrece una visión sustentable a través de la siguiente figura. 
Figura 6: La captura de valor en tres áreas clave.

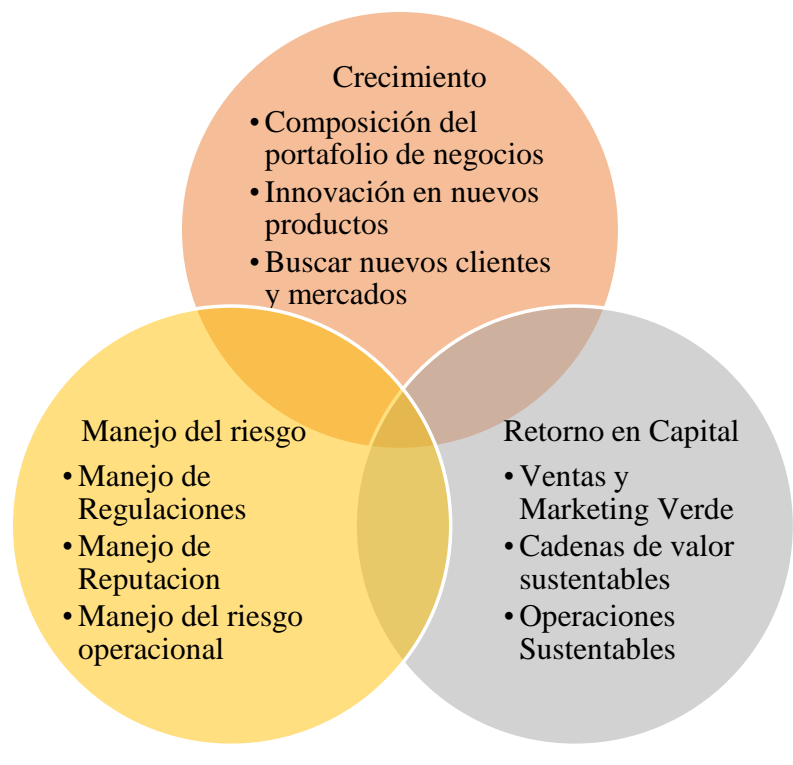

Fuente: Datos del artículo "The business of sustainability: Putting it in practice" de la consultora McKinsey y Company (2011), p.3.

En el aspecto crecimiento, las compañías deben revisar su portafolio de productos para determinar el impacto potencial de las tendencias que pueden llevar a nuevas oportunidades de negocios. Otro punto importante es alinear oportunidades sustentables con sus estrategias y lograr identificar potenciales clientes. En la encuesta que toma como base para su análisis la consultora, $88 \%$ de los directivos en empresas líderes dijeron que siempre buscan nuevas oportunidades para invertir en sostenibilidad.

El retorno en capital se da cuando las empresas reducen sus costos operacionales (reducción de agua o energía) generando operaciones sustentables desde los costos fijos. Otra forma de aumentar el retorno en capital es transformando las cadenas de valor para reducir costos de materiales o insumos que se usan frecuentemente y son fácilmente sustituibles, este punto también genera un efecto ambiental dado que se cambia un insumo dañino para el medio ambiente por uno eco amigable. En la encuesta, $78 \%$ de los directivos dijeron que ya habían integrado casi o en su totalidad la sostenibilidad en sus cadenas de valor.

El manejo del riesgo empieza con la detección de riesgos significativos que puedan retrasar o detener el funcionamiento de la empresa. Estos riesgos 
provienen, principalmente, del cambio climático, la escasez de materia prima y problemas sociales o con los gobiernos (boicot o demoras en la otorgación de permisos).

Para el aspecto social de sostenibilidad, Paul Klein (2011) en el artículo "The Five elements of the Best CSR Programs" de la revista Forbes, muestra una visión sustentable a través de la siguiente figura.

Figura 7: Responsabilidad Social Empresarial (RSE).

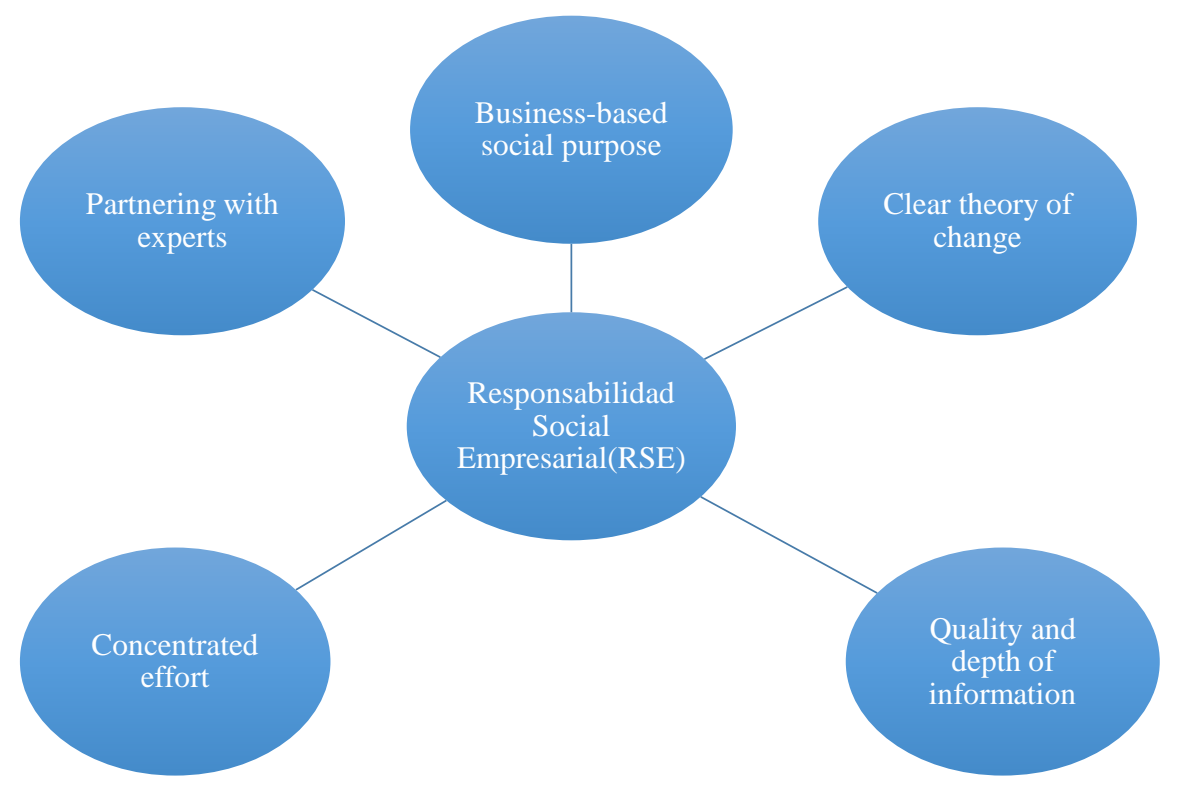

Fuente: Elaboración Propia con datos del articulo "The Five elements of the Best CSR Programs" de la revista Forbes.

El propósito social debe estar basado en la actividad económica de la compañía. Es decir, si es una empresa agrícola debe procurar que los propósitos sociales sean dirigidos a contrarrestar o apoyar causas como apoyar a los pequeños campesinos con campañas de mejora de las condiciones de siembra o darles los residuos de su actividad agrícola (cascaras del arroz o de la palma).

La RSE dejo de ser un tema de moda en las empresas para poder ser un valor empresarial, lo que significa que los esfuerzos sociales de las compañías deben ser lo más innovadores posibles para lograr diferenciarse. Por ejemplo, si las compañías de un determinado sector están ayudando a construir huertas 
comunitarias, se puede hacer un proyecto donde esa huerta sea la que suministre a restaurantes reconocidos de la ciudad.

La calidad y profundidad de la información relevante a los proyectos sociales debe ser una prioridad para poder desarrollar un programa abordando un problema de una manera directa y efectiva. No es suficiente con decir que un determinado producto está afectando la salud pública, se debe realizar una investigación a fondo para determinar que elemento específico es el causante de este incidente.

Las compañías no deben concentrarse en múltiples problemas sociales a la vez, dado que no les prestaran la suficiente atención a todos. Es mejor enfocar todos sus recursos internos y externos en un determinado problema para poder dar con una solución.

Se debe contar con la ayuda de expertos en los temas que se quieren intervenir por parte de las empresas. Esto se debe a que el RSE debe tener un alto grado de credibilidad para poder comenzar a operar. Si se quiere construir un hospital o una escuela en un municipio se debe contar con personas de la comunidad académica o médica para conocer donde sería más apropiada la presencia de los mismos.

Para el aspecto ambiental, En el cuaderno de investigación "Guía para el mejoramiento de la responsabilidad social en las pequeñas y medianas empresas de la ciudad de Bogotá" (2013) de los autores Luz Janeth Lozano y Nelson Díaz Cáceres, se documenta el modelo MMGO Componente RSE posee una sección de medio ambiente, que se explica con la siguiente figura.

Figura 8: Modelo MMGO - Componente RSE.

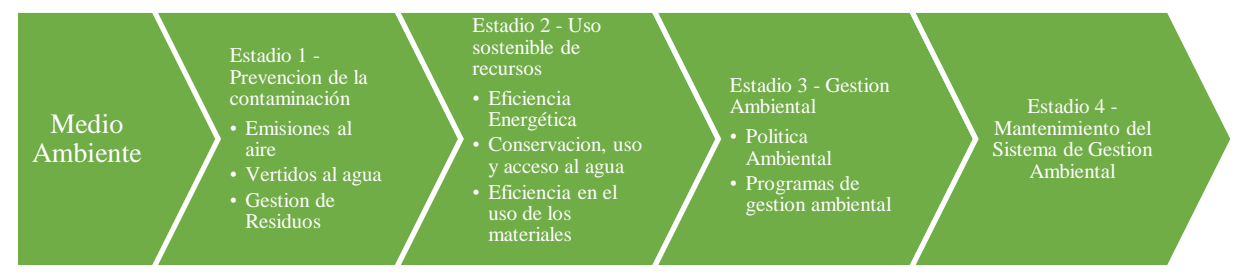

Fuente: Creación propia con datos del cuaderno de investigación "Guía para el mejoramiento de la responsabilidad social en las pequeñas y medianas empresas de la ciudad de Bogotá” de la Universidad EAN. Díaz y Lozano 2011. 
El objetivo del modelo MMGO es ayudar a las pequeñas y Medianas empresas (Pymes) en su transformación hacia empresas competitivas, con prácticas de gestión para facilitar el alcance de sus resultados. En el caso de la parte del medio ambiente, el objetivo final es la generación de un sistema de gestión ambiental (SGA) para poder cumplir con los compromisos ambientales que suscriban las empresas.

En el estadio 1, las empresas deben prevenir la contaminación que se dan en sus actividades productivas por medio de las emisiones al aire, que pueden contener químicos nocivos para el ambiente o la salud humana. Otro punto importante es evitar los vertimientos a las fuentes hídricas, directa o indirectamente, que se originen por medio de sus operaciones o el uso de sus productos. El último inciso de este estadio es la gestión de recursos que busca evitar que los residuos generados por medio de las actividades de las organizaciones provoquen una contaminación de cualquier tipo. Para lograr este fin se debe seguir la jerarquía de reducción de los residuos que consiste en los siguientes procesos.

Figura 9: Modelo MMGO - Reducción de los residuos.

\begin{tabular}{|l|l} 
Reduccion de \\
los residuos
\end{tabular}$\quad \begin{gathered}\text { Reduccion } \\
\text { en la fuente }\end{gathered} \quad$ Reutilización $\quad\left\{\begin{array}{c}\text { Reciclado y } \\
\text { procesamie } \\
\text { nto }\end{array} \quad \begin{array}{c}\text { Tratamiento } \\
\text { disposición } \\
\text { final de } \\
\text { Residuos }\end{array}\right\rangle$

Fuente: Creación propia con datos del cuaderno de investigación "Guía para el mejoramiento de la responsabilidad social en las pequeñas y medianas empresas de la ciudad de Bogotá” de la Universidad EAN. Díaz y Lozano 2011.

Cuando estos planes de acción estén en marcha y dando resultados, el estadio 2 ofrece más herramientas para poder seguir consolidando la creación del SGA. La eficiencia energética es una acción por la cual se busca la reducción en el consumo de energía en las instalaciones, maquinas, transportes, entre otras fuentes de consumo de energía en las operaciones de las empresas. Además, se busca el cambio energético de energía eléctrica producida por el carbón o la madera por otras más renovables como la energía solar, eólica, geotérmica o hidroeléctrica.

La conservación uso y acceso al agua se refiere al acceso a suministro de agua potable segura y fiable y a los servicios sanitarios, las empresas deben asegurarse de conservar, reducir y reutilizar el agua en sus operaciones y la estimulación de la conservación del agua en su esfera de influencia. Finalmente, la eficiencia en el uso de materiales se refiere a la reducción del deterioro ambiental que ocasiona el uso de materias primas en los procesos de producción, productos terminados o 
entrega en los servicios de las compañías (ej. Los plásticos en los empaques de carnes).

Al realizarse los estadios anteriores y tener en funcionamiento las diversas actividades para la reducción de la huella ambiental de las empresas, se debe crear un documento donde se especifique la política ambiental de la empresa, definida por la alta dirección. En esta política ambiental, debe estar escrito como se van a identificar los aspectos medioambientales de las actividades de la empresa, así como de sus productos o servicios. Otro punto importante es la definición de un proceso para conocer las diferentes regulaciones ambientales que aplican a la empresa. Por último, se debe implementar un procedimiento para lograr los objetivos y metas ambientales, con base en sistemas de medición y de revisión y ajuste. El estadio 4 es el mantenimiento del SGA con los controles y ajuste a los que haya lugar.

En el artículo "Valor Compartido, más allá de las empresas" publicado en la revista Responsabilidad Sostenibilidad (2013), Juana García Duque argumenta que el concepto de Creación de Valor Compartido (CVC) esta incrustado en el corazón de los negocios. Esto crea oportunidades de negocio con beneficios sociales y ambientales tangibles, aunque las herramientas para poner en práctica esta nueva forma de hacer negocios todavía no se han desarrollado para todos los sectores.

Es el gobierno y no las empresas quien debe dar los lineamientos para que la apropiación del CVC se de en todos los sectores de las sociedades, no solamente en el empresarial. Un sector que debe influir más en el CVC es el de la cooperación internacional que puede aportar experiencias de otros países donde acciones sociales y medioambientales han tenido éxito en la transformación de la sociedad. La autora considera que es necesaria una sinergia entre las empresas, el gobierno y la cooperación internacional para generar un mayor impacto y un mejor conocimiento de las problemáticas para generar resultados sociales que lleven a la innovación, crecimiento e impacto social a largo plazo.

Persons (2012) reconoce el triple balance o triple objetivo (personas, planeta y productividad) propuesto por Elkington como el fundamento de la sostenibilidad. Este profesor de la Universidad Rider cita al IMA (Institute of Management Accountants) para complementar la conceptualización de este tema. El instituto considera que la sostenibilidad es la habilidad de la organización para conocer, entender y considerar todos los factores que afectan su valor y condicionan sus posibilidades de operar en el futuro. Adicionalmente indica que una junta directiva no representa a sus grupos de interés cuando no considera los impactos sociales y ambientales tanto como los aspectos económicos tangibles e intangibles que contribuyen a la habilidad de mantener la empresa. 
Walt Freese (2007), por su parte, toma a Paul Hawken como punto de partida para construir su propio concepto de sostenibilidad. Para él, la sostenibilidad se debe enfocar en tres aspectos fundamentales: lo que las empresas toman, lo que hacen y lo que tanto estas como sus clientes desperdician. Esto integra el concepto de sostenibilidad a las actividades cotidianas de las organizaciones y a la manera en que estas se desarrollan.

Smith (2013) explica que la sostenibilidad busca crear valor (en los aspectos anteriormente explicados por otros autores) en el largo plazo, a través de la participación de los grupos de interés y la transparencia de las organizaciones. Es clave resaltar que las políticas de sostenibilidad no buscan resultados inmediatos, sino desarrollo general en el largo plazo.

Con respecto a la sostenibilidad en las empresas, Don Schjeldahl (2013) describe las dos formas en que las organizaciones se han enfocado en ella: el enfoque externo, que consiste en incluir prácticas extras a las actividades de la empresa, de manera que la organización tenga la oportunidad de devolver beneficios a la comunidad; y el enfoque interno que consiste en integrar los objetivos de sostenibilidad a los propios de la empresa, de manera que estén estrechamente relacionados con la estrategia operativa y las actividades diarias de la organización. Aunque el primer enfoque es relevante para la consecución de los objetivos de la sostenibilidad empresarial, el segundo constituye el reto al que se enfrentan las organizaciones actualmente, pues es la manera más eficiente de lograr el desarrollo económico propio y generar cambios positivos en el entorno.

Por otra parte, Marc Epstein y Adriana Buhovac (2014) ofrecen una delimitación del concepto (en el contexto de la responsabilidad corporativa) aún más profunda y detallada, al establecer 9 principios que la componen: ética, gobierno, transparencia, relaciones de negocio, retorno financiero para inversionistas y prestamistas, participación de la comunidad y desarrollo económico, valor de los productos y servicios, prácticas de empleo y protección del medio ambiente. Estos principios sirven como guía para las empresas que buscan integrar la sostenibilidad a sus actividades.

Así mismo, Turan y Needy (2013) citan a Dyllick y Hockerts, quienes consideran que la sostenibilidad debe tener en cuenta las necesidades de sus grupos de interés tanto directos como indirectos. La mención de estos últimos deja clara la necesidad de evaluar todos los potenciales niveles de impacto que las acciones de las empresas tienen no solo sobre los grupos e individuos con los que interactúan directamente, sino además sobre todos los actores que constituyen su entorno. Estos mismos autores citan a Dow Jones Sustainability Indexes, una organización encargada de evaluar y asesorar la sostenibilidad corporativa, que a las definiciones anteriores agrega que la sostenibilidad se alcanza a través del 
aprovechamiento de las oportunidades y el adecuado manejo de los riesgos que se derivan de los desarrollos en las tres dimensiones de la sostenibilidad.

Kurzrok y Hund (2013) establecen la importancia que tiene para las organizaciones el intercambio de información acerca de la sostenibilidad con sus grupos de interés. Estos autores consideran que los reportes de sostenibilidad pueden afectar el desempeño de las empresas en el corto, mediano y largo plazo. La selección de la información incluida en estos reportes es vista como uno de los factores críticos para lograr prácticas sostenibles: el documento muestra que la disposición de las organizaciones para asumir responsabilidad por las acciones que puedan tener impacto sobre los grupos de interés representa un cierto nivel de compromiso por parte de las empresas.

Se debe recalcar que, aunque existen organismos externos que evalúan la sostenibilidad corporativa, las empresas son, en última instancia, quienes proveen información sobre sus prácticas y quienes deciden si y cómo integrar la sostenibilidad empresarial a sus actividades. Por este motivo, la confianza generada entre los grupos de interés y las organizaciones, así como la que se da al interior de las mismas, influencia directamente la sostenibilidad de las empresas y la percepción que los agentes externos tienen de esta.

Así pues, la sostenibilidad empresarial está estrechamente relacionada con la confianza, ya que tanto el adecuado intercambio de información, como los principios descritos por Epstein y Buhovac y los tres pilares del concepto (crecimiento económico, cuidado del entorno social y protección del medio ambiente) dependen en gran medida de la confianza existente entre las organizaciones y sus grupos de interés, así como de la que se genera al interior de las mismas.

\section{Conclusiones}

En este trabajo de investigación se ha presentado un análisis de las variables que pueden influir en la creación de confianza en organizaciones sostenibles a partir de la revisión teórica de varios factores importantes en las empresas, con los cuales se pueden realizar hipótesis de compañías que tengan algunas de los factores mencionados. La confianza es, por tanto, un factor clave para el éxito de cualquier negocio; para que este tenga alto índices de sostenibilidad, es de suma importancia que la confianza sea un intangible que se pueda cuantificar y medir, así como un componente clave en los espacios de trabajo como factor relacional entre los empleados y el empleador.

La confianza juega un papel relevante en la construcción de equipos, en la funcionalidad y en la productividad. Debe ser vista como la llave para un buen desempeño organizacional y el éxito de las relaciones interpersonales. Estas 
relaciones de confianza logran que aun un plan organizacional defectuoso funcione, ya que proveen las llaves las buenas comunicaciones, crean las condiciones para el trabajo en equipo, rectifican las acciones realizadas fuera de tiempo y suavizan el impacto de un ambiente organizacional explosivo y difamatorio. Las relaciones de confianza crean las condiciones para el éxito de cualquier empresa.

En la investigación se percibe como existen factores que influyen en la confianza tan distinta entre ellos como la reputación y la transparencia, a los cuales con un cambio mínimo se tienen dos compañías que generan confianza de una manera distinta. La confianza como valor organizacional puede ser adoptado y gestionado como valor relacional por cuanto contribuye eficazmente a reducir la complejidad, el riesgo, la incertidumbre, equilibra el poder y limita el odio o la misma venganza. En consecuencia, la confianza debe cultivarse hacia dentro y hacia afuera de la organización. También, se observó que las empresas sostenibles realizan muchas inversiones en la parte económica, social y ambiental que permitan que todos los grupos de interés perciban que la llegada de la compañía es un beneficio para ellos.

La confianza auténtica es totalmente consciente de sí misma, consciente de sus propias condiciones y limitaciones, abierta a nuevas e incluso inimaginables posibilidades, sobre la base de la elección y la responsabilidad en lugar de las operaciones mecánicas de la previsibilidad, la dependencia y rigidez. La confianza auténtica es muy consciente de los riesgos y dispuesto a enfrentar la desconfianza y a superarla.

\section{Referencias}

Almeida, M. A. (2009). La transparencia de las empresas en internet para la confianza de los accionistas e inversores: un análisis empírico. Cuadernos De Administración (01203592), 22(38), 11-30.

Anderson, A. R. (2013). Good Employees Make Mistakes. Great Leaders Allow Them To. Recuperado el 13 de octubre de 2015 de: http://www.forbes.com/sites/amyanderson/2013/04/17/good-employees-makemistakes-great-leaders-allow-them-to/.

Arrow, K. J. (1971). Essays in the Theory of Risk Bearing, Chapter 3, pp. 90-133. Chicago: Markham Publishing Co.

Bosovsky, G. (2011). El problema de la credibilidad y la reputación corporativa. Tiempo de Mercadeo, 31, 27-31. 
Bracey, L. (2012). The Importance of Business Reputation. Recuperado el 15 de octubre de 2015 de: http://www.businessinfocusmagazine.com/2012/10/theimportance-of-business-reputation/.

Buzzota, V. (May/2001). Trust as a Style. Recuperado el 27 de julio de 2015, de Communicare: http://www.communicare.com/DT/pdf/Value\%20Added\%20Documents/Trust $\% 20$ As\%20A\%20Style_VBuzzotta,\%202001.pdf

Cooper, Robert. (1998). La inteligencia emocional aplicada al liderazgo y a las organizaciones. Editorial Norma.

Duque J. G. (2013) "Valor Compartido, mas alla de las empresas. Responsabilidad y Sostenibilidad, 57, p. 32.

Epstein, M. J., y Buhovac, A. R. (2014). Making sustainability work: Best practices in managing and measuring corporate social, environmental, and economic impacts. Berrett-Koehler Publishers.

Freese, W. (2007). The business case for sustainability. New Directions For Institutional Research, 2007(134), 27-35. doi:10.1002/ir.210

Gil Lafuente, A. M., y Paula, L. B. (2011). La gestión de los grupos de interés: una reflexión sobre los desafíos a los que se enfrentan las empresas en la búsqueda de la sostenibilidad empresarial. Revista de Métodos Cuantitativos para la Economía y la Empresa, 11, 71-90.

Russell, Hardin. (2002). Trust and Trustworthiness. New York, Russell Sage Foundation.

Hernández, A. M. (2010). La confianza en las organizaciones. Una experiencia desde "Great Place to Work Institute " de México. México: Great Place to Work.

Hund, G., y Kurzrok, A. J. (2013). Beyond compliance: Integrating nonproliferation into corporate sustainability (No. PNNL-SA-90974). Pacific Northwest National Laboratory (PNNL), Richland, WA (US).

Illes, Katalin., y Mathews, Martin. (2015). Leadership, trust and communication: Building trust in Companies through effective leadership communication, University of Westminster. Recuperado el 16 de julio de 2015 de: http://www.allthingsic.com/wp-content/uploads/2015/02/Trustreport-1.pdf

Kee, Herbert W., y Knox, Robert E. (2004). Conceptual and Methodological Considerations in the Study of Trust and suspicion, The Journal of Conflict Resolution, Vol. 14, № 3, Sep, pp. 357 - 366.

Klein, Paul (2011). The Five Elements of the Best CSR Programs. Recuperado el 7 de septiembre de 2015 de: http://www.forbes.com/sites/csr/2011/04/26/the-fiveelements-of-the-best-csr-programs/. 
Kramer, R. M. (1999). Trust and distrust in organizations: Emerging perspectives, enduring questions. Annual Review of Psychology, 50(1), 569.

Lewis, J. D., y Weigert, A. (1985). Trust as a Social Reality. Social Forces, 63(4), 967985.

Loep, H. y McNulty, E. J. (2014). Don't trust your company's reputation to the Quants. Recuperado el 16 de octubre de 2015 de: https://hbr.org/2014/08/dont-trustyour-companys-reputation-to-the-quants.

Lozano, L. J., y Cáceres, N. (2013). “Guía para el mejoramiento de la responsabilidad social en las pequeñas y medianas empresas de la ciudad de Bogotá. Universidad $E A N$, Recurso electrónico encontrado en el Catalogo SIBEAN.

Lozano, R. (2012). Orchestrating Organisational Changes for Corporate Sustainability. Greener Management International, (57), 43-64.

Llopis, G. (2012). Powerful things happen when a leader is transparent. Recuperado el 11 de octubre de 2015 de: http://www.forbes.com/sites/glennllopis/2012/09/10/5powerful-things-happen-when-a-leader-is-transparent/.

Márquez, A. (2013) La justicia relacional como círculo virtuoso. Recerca, Revista de Pensament i Anàlisi, 14, 117-134.

Mayol, D. (2007). La confianza en la organización: ¿valor o valiosa? Logoi, (12),37-51.

McKinsey. (2011). The business of sustainability: Putting it into practice. Recuperado el 3 de septiembre de 2015 de: http://www.mckinsey.com/ /media/mckinsey/dotcom/client_service/sustainabi lity/pdfs/putting_it_into_practice.ashx.

Mintzberg, H. (1992). El poder en la organización. Barcelona: Ariel.

Persons, O. (2012). Incorporating Corporate Social Responsibility and Sustainability Into a Business Course: A Shared Experience. Journal of Education For Business, 87(2), 63-72. doi:10.1080/08832323.2011.562933

Pinillos, A. A., y Fernández, J. L. F. (2011). De la RSC a la sostenibilidad corporativa: una evolución necesaria para la creación de valor. Harvard-Deusto Business Review, 207, 5-21.

Projection Central. (2014). How to Communicate Up, Down, and Sideways in Your Company. Recuperado el 12 de octubre de 2015 de: http://projectioncentral.com/blog/how-to-communicate-up-down-andsideways-in-your-company/.

Redacción Portafolio (2015) Academia/ Confianza, motor de sostenibilidad empresarial. Recuperado de: http://www.portafolio.co/opinion/redaccionportafolio/academia-confianza-motor-sostenibilidad-empresarial-24630

Restrepo, M. L. (2007). Construir la confianza, un verdadero arte. Latinpyme, 36, 32-33. 
Robbins, S. (2004). Comportamiento Organizacional. México: Prentice Hall.

Rousseau, D. M., Sitkin, S. B., Burt, R. S., y Camerer, C. (1998). Not so different after all: A cross-discipline view of trust. Academy of management review, 23(3), 393404.

Schjeldahl, D. (2013). The coming era of sustainability. Economic Development Journal, $12(4), 5-12$.

Schaefer, M. (2013). Como ganarse a un consumidor cada vez más poderoso. America Empresarial, 6, 40-51.

Schramm, J. (2015). Respect And Trust Top The List Of Most Important Employee Job Satisfaction Factors. Recuperado el 13 de octubre de 2015 de: http://blog.shrm.org/blog/respect-and-trust-top-the-list-of-most-importantemployee-job-satisfaction.

Smith, T. M. (2013). Climate change: Corporate sustainability in the supply chain. Bulletin of The Atomic Scientists, 69(3), 43-52. doi:10.1177/0096340213487310

Starnes, B., Truhon, S., McCarthy, V. (2010). Organizational Trust: Employee-Employer Relationships. Recuperado el 12 de agosto de 2015 de: http://rube.asq.org/hdl/2010/06/a-primer-on-organizational-trust.pdf

Tan, H. H., y Lim, A. H. (2009). Trust in Coworkers and Trust in Organizations. Journal of Psychology, 143(1), 45-66.

Topa, G., Palací, F. y Morales, J.F. (2004). La ruptura de contrato psicológico y las respuestas del trabajador. ¿Relaciones mediadas por la confianza organizacional? Revista de Psicologia del Trabajo y de Las Organizaciones, 20(1), 31-45.

Turan, F. K., y Needy, K. L. (2013). A Quantitative Decision Model Towards Maximizing Organizational Sustainability. Engineering Management Journal, 25(1), 3-18. 